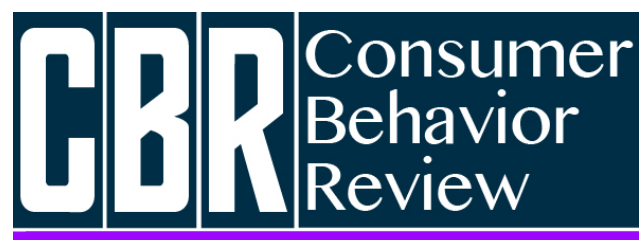

Revista Comportamento do Consumidor
Pereira, V. F., \& Quintão, R. T. (2020). Singularização dos Objetos de Segunda Mão: Um estudo no contexto de brechós de luxo. Consumer Behavior Review, 4(2), 118127.
ISSN: 2526-7884

Editor: Prof. Dr. Marconi Freitas da Costa Journal's e-mail: cbr@ufpe.br
Evaluation: Double blind review

Received: 13 de fevereiro de 2020

Accepted: 28 de abril de 2020

\title{
SINGULARIZAÇÃO DOS OBJETOS DE SEGUNDA MÃO: UM ESTUDO NO CONTEXTO DE BRECHÓS DE LUXO
}

\author{
Singularization of Second-Hand Objects: A study of luxury thrift stores
}

\author{
Verônica Fujise Pereira ${ }^{1}$ \\ ORCID: http://orcid.org/0000-0002-0056-8443 \\ E-mail:veronicafujise@hotmail.com \\ Ronan Torres Quintão ${ }^{2}$ \\ ORCID: http://orcid.org/0000-0001-7200-6477 \\ E-mail: ronan.torres@ifsp.edu.br
}

\footnotetext{
${ }^{1}$ Centro Federal de Educação Tecnológica de Minas Gerais, Belo Horizonte, Brasil

${ }^{2}$ Instituto Federal de Educação, Ciência e Tecnologia de São Paulo, Jacareí, Brasil
}

\begin{abstract}
Resumo
Pesquisas do campo da cultura de consumo investigam sobre como revestimos os objetos de significados e os retiramos do status de mercadoria, tornando-os singularizados. Há ainda estudos que se concentraram em compreender o movimento de retorno dos objetos singularizados ao estado de mercadoria, sendo mercantilizados novamente ou descartados. Seguindo esta corrente de pesquisa, este estudo busca compreender como os objetos de segunda mão comercializados no mercado retomam seu status singularizado. Para alcançar os objetivos aqui propostos foi realizada uma
\end{abstract}

\begin{abstract}
Consumer culture field investigates the process of how we attribute meaning to objects and remove them from the status of commodity, turning them into unique items. There are studies that focused on understanding the movement of returning singular objects to the status of commodity, being commoditized again or discarded. Following this path of research, this study seeks to understand how second-hand objects offered in the market regain a singular status. To achieve the objective, we carried out a qualitative research over 18 months using
\end{abstract}


pesquisa qualitativa durante 18 meses utilizando brechós de luxo como contexto empírico. Os dados foram coletados por meio de entrevistas em profundidade e netnografia, sendo analisados de forma hermenêutica. Como resultado, a pesquisa verificou que os objetos de segunda mão retomam seu status singular, por meio de duas estratégias adotadas pelos vendedores e consumidores: (1) resgate da biografia do objeto e (2) potencial de diferenciação do objeto. Os resultados da pesquisa auxiliam, sobretudo, na ampliação do entendimento sobre o movimento do objeto e mudança de seus status (mercadoria ou singular) nas relações comerciais entre consumidores e vendedores.

Palavras-Chave: Singularização do objeto, Mercadoria de segunda mão, Brechós. luxury thrift stores as empirical context. Data were collected through both in-depth interviews and netnography, being analyzed through a hermeneutic approach. As a result, we found that second-hand objects return to their singular status through two strategies adopted by sellers and consumers: (1) retrieval of the object's biography, and (2) the object singularity potential. The results also help to broaden the understanding on the movement of the object and its status (commodity or singular) in the commercial relationships between consumers and sellers. Keywords: Objects singularity, Second-hand product, Thrift stores.

Esta obra está licenciada com uma Licença Creative Commons Atribuição 4.0 Internacional.

\section{INTRODUÇÃO}

Diversos estudos no campo de pesquisa da cultura de consumo investigaram sobre a influência do mundo material na vida dos consumidores (Batinga, Pinto, \& Guimarães, 2019, Borgerson, 2005, Miller, 2013). Dentre estes estudos, uma corrente de pesquisa busca entender como os consumidores escolhem objetos e os retiram de seu status de mercadoria, tornando-os singularizados (Belk, Wallendorf, \& Sherry, 1989; Curasi, Price, \& Arnould, 2004; Kopytoff, 2008; Miller, 2007). Os objetos são singularizados por meio de práticas sucessivas de investimento e desinvestimento de significados nos objetos realizadas pelos consumidores. Enquanto o objeto singularizado permanece importante para o consumidor, ele está protegido da mercantilização (Epp \& Price, 2010). No entanto, diversas circunstâncias ameaçam o estado singular do objeto durante a sua biografia, podendo, assim, retornar à esfera mercantil, sendo mercantilizados novamente, ou descartados (Epp \& Price, 2010; Herrmann, 1997; Lastovicka \& Fernandez, 2005).

A movimentação do significado do objeto envolvendo sua mercantilização, singularização e mercantilização foi explicada pela literatura em contextos tais como decisão sobre localização da mesa de cozinha da família em uma nova casa (Epp \& Price, 2010) e escolha e cuidados com vestido de casamento (Lastovicka \& Fernandez, 2005). Entretanto, em brechós de luxo, por exemplo, há produtos que passam por esse mesmo processo, mas que retomam a condição de produtos singularizados após serem vendidos novamente.

Dessa forma, o contexto de brechós de luxo possibilita a ampliação do entendimento sobre o processo de movimentação do significado dos objetos, acrescentando novas fases no processo de mercantilização e singularização dos objetos. Portanto, o trabalho busca investigar: como os objetos de segunda mão comercializados no mercado retomam seu status singularizado? Para responder a essa pergunta de pesquisa foi escolhido o contexto de brechós de luxo que comercializam roupas e acessórios de segunda mão, sendo utilizadas, como método de pesquisa, entrevistas em profundidade e netnografia.

0 artigo explica o processo de nova singularização de um objeto usado. 0 objeto usado mercantilizado pelo brechó retoma sua condição de singularizado por meio de duas estratégias de mercado: (1) resgate de sua biografia e (2) potencial de diferenciação. A seguir, o artigo apresenta os estudos sobre biografia dos objetos e sua singularização, assim como o consumo de objetos de 
segunda mão. Posteriormente, o mercado de segunda é caracterizado e descrito como local de ocorrência do fenômeno estudado. Posteriormente, são apresentados os caminhos metodológicos percorridos para elaboração do estudo, incluindo a coleta e análise dos dados. Por fim, são apresentadas as análises e considerações finais da pesquisa, assim como as sugestões para estudos futuros.

\section{SINGULARIZAÇÃO DOS OBJETOS}

0 intercâmbio de coisas, objetos e mercadorias é um dos elementos centrais da vida social humana (Kopytoff, 2008). Uma mercadoria é algo que tem valor de troca e de uso. Tudo que pode ser trocado é, nesse momento, uma mercadoria, seja qual for o destino reservado a ela (Kopytoff, 2008). A concessão de um preço a esses bens permite que eles circulem na economia de mercado (Herrmann, 1997). Entretanto, o estado do objeto como mercadoria não é, necessariamente, terminal. Ser uma mercadoria pode ser apenas uma fase da biografia do objeto e não um estado permanente. 0 objeto pode ser removido da esfera de troca, tornando-se singularizado pelo consumidor.

A singularização se refere à forma como os consumidores personalizam e integram os objetos em suas vidas (Miller, 2007). A singularização é essencial para que objetos resistam à mercantilização (Kopytoff, 2008). Os objetos carregam histórias, e muitas vezes têm papel importante na vida de uma família ou de um indivíduo. Os objetos especiais têm significados particulares que definem seu valor, independentemente do valor de mercado. Em muitos casos, estes objetos são insubstituíveis (Curasi, Price, \& Arnould, 2004).

Contudo, os objetos podem entrar e sair do status de mercadoria ou de singularizado como parte da sua "história de vida" (Herrmann, 1997; Kopytoff, 2008). As mercadorias podem se tornar singularizadas, assim como os objetos singularizados podem retornar à esfera mercantil, no momento em que os contextos mudam (Lastovicka \& Fernandez, 2005; Epp \& Price, 2010). Dessa forma, os objetos podem ser singularizados sendo carregados de identidades pessoais dos consumidores que os possuem, ou podem ser commodities sendo alienados de seus possuintes (Herrmann, 1997).

Os objetos transitam dentro e fora do estado de mercadoria ou estado singular e tais movimentos podem ser rápidos ou lentos, reversíveis ou terminais, regulamentares ou conflitantes (Appadurai, 2008). Durante a singularização, alguns objetos têm seu valor monetário apenas desativado, sem ser eliminado. Por conseguinte, eles sempre são commodities potenciais, já que possuem um valor de troca caso retornem à esfera mercantil e sejam revendidos (Kopytoff, 2008).

Os estudos do campo da cultura de consumo explicam como os objetos são singularizados pelos consumidores (Belk, Wallendorf, \& Sherry, 1989; Curasi, Price, \& Arnould, 2004; Kopytoff, 2008; Miller, 2007) e retornam à esfera mercantil (Epp \& Price, 2010; Herrmann, 1997; Lastovicka \& Fernandez, 2005). Nosso estudo, entretanto, busca ampliar o entendimento sobre a mudança de status dos objetos no mercado, explicando como bens singularizados pelo consumidor, retornam ao mercado como objetos de segunda mão em brechós de luxo e são singularizados novamente no mercado.

\section{OBJETOS DE SEGUNDA MÃO E BRECHÓS DE LUXO}

A venda de bens usados transmite algo dos proprietários originais, sejam sinais físicos de desgaste, como manchas ou arranhões, associações emocionais ou sensação de contágio, por meio do qual o consumidor singulariza ou sacraliza o objeto (Belk, 1988; Belk; Wallendorf, \& Sherry, 1989; Herrmann, 1997; Fernandez \& Lastovicka, 2011). Desse modo, os bens que foram comprados como mercadorias são transformados por posse pessoal do consumidor em itens únicos e singulares, que se apropria da história do objeto de segunda mão (Roux \& Guiot, 2008).

Para alguns consumidores, uma das principais atrações de compras em mercados, tais como como as vendas de garagem, brechós, bazares e mercado de pulgas (Herrmann, 1997; Sherry Jr, 1990), é o fato dos produtos já terem sido utilizados anteriormente e possuírem uma história (histórias de vida do objeto, Kopytoff, 2008). Tradicionalmente, a compra de objetos de segunda mão era limitada aos locais de comércio de produtos usados, sendo considerados menos dispendiosos e financeiramente mais atraentes para certas classes sociais (Roux \& Guiot, 2008; Williams \& Paddock, 2003). Atualmente, as lojas de segunda mão, os mercados e a Internet aceleraram a disseminação 
desse tipo de troca, respondendo a um aumento da demanda dos compradores e dos vendedores (Roux \& Guiot, 2008).

Em relação aos produtos de luxo de segunda mão, estes podem ter significados ainda mais profundos para seus proprietários, pois desenvolvem relações mais estreitas com esse tipo de produto. Isso ocorre porque, nesse caso, os consumidores têm a sensação de assumirem papéis mais ativos ao adquirir esses bens (Turunen \& Leipämaa-Leskinen, 2015). Particularmente, os bens de luxo de segunda mão possuem significados específicos para seus consumidores, como por exemplo, emoções e compromissos emocionais estão relacionados a encontrar esses bens. Além disso, Turunen e Leipämaa-Leskinen (2015) explicam que os significados associados a esse tipo de consumo mostram que a história anterior e a história por trás do item evocam um forte compromisso emocional com a posse do objeto de luxo de segunda mão.

Nosso estudo avança no entendimento sobre o mercado de produto de luxo de segunda mão (Turunen \& Leipämaa-Leskinen, 2015; Ferraro, Sands, \& Brace-Govan, 2016), explicando o movimento do significado do produto no mercado.

\section{MÉTODOS DE PESQUISA}

Para compreender como os objetos de segunda mão comercializados no mercado retomam seu status singularizado, realizamos uma pesquisa com abordagem qualitativa durante 18 meses com foco no mercado de roupas e acessórios de segunda mão comercializados em brechó de luxo, a partir de uma perspectiva interpretativista, utilizando entrevistas em profundidade e netnografia, com o intuito de compreender em profundidade o fenômeno estudado.

Para entender inicialmente o contexto estudado, foi realizada netnografia (Kozinets, 2014) que busca entender o comportamento do consumidor nas mídias sociais e no ambiente virtual como um fenômeno cultural (Elk, Fischer, \& Kozinets, 2013). Com o avanço tecnológico, a internet se tornou referência no sentindo de difundir as informações de moda, com versões online de jornais, revistas especializadas, blogs e redes sociais (Hinerasky, 2010). Dessa forma, a primeira autora do artigo coletou dados de blogs e postagens em grupos de Facebook durante 1 ano e meio com o objetivo de realizar uma imersão prolongada no mercado de roupa de segunda mão (Belk, Fischer, \& Kozinets, 2013). Os blogs e sites brasileiros estudados foram: "Um ano sem Zara", "Modices", "Hoje vou assim", "Tudo Orna", "Fashionismo", "Review Slow Living", "Slow Down Fashion", "Carol Burgo", "Petiscos", "Trocaria" e "Diga Xs".

A "blogosfera" (Mcquarrie, Miller, \& Phillips, 2013; Scaraboto \& Fischer, 2013) possui um grande número de blogs dedicados à moda, com diversos posts relacionados ao consumo em brechós de luxo. Nesse caso, o critério adotado para escolha dos blogs acompanhados foi a consonância com o contexto estudado uma vez que, inicialmente, seria necessário obter conhecimento de como acontece esse tipo de consumo, os relatos das blogueiras e leitoras, além de referências a brechós, bazares ou locais de venda de produtos de segunda mão, as características das autoras e do público, os tópicos abordados e também o conhecimento prévio dos pesquisadores.

Com o intuito de aprofundar a compreensão e análise do fenômeno estudado, a primeira autora também realizou entrevistas em profundidade (Belk, Fischer, \& Kozinets, 2013) com 10 consumidoras e 3 proprietárias de brechós (Figura 1). As entrevistas realizadas por meio de indicações, pelo método bola de neve (Belk, Fischer, \& Kozinets, 2013). 0 tempo médio das entrevistas foi de uma hora, totalizando 13 horas de áudio. As entrevistas foram gravas e transcritas para posterior análise.

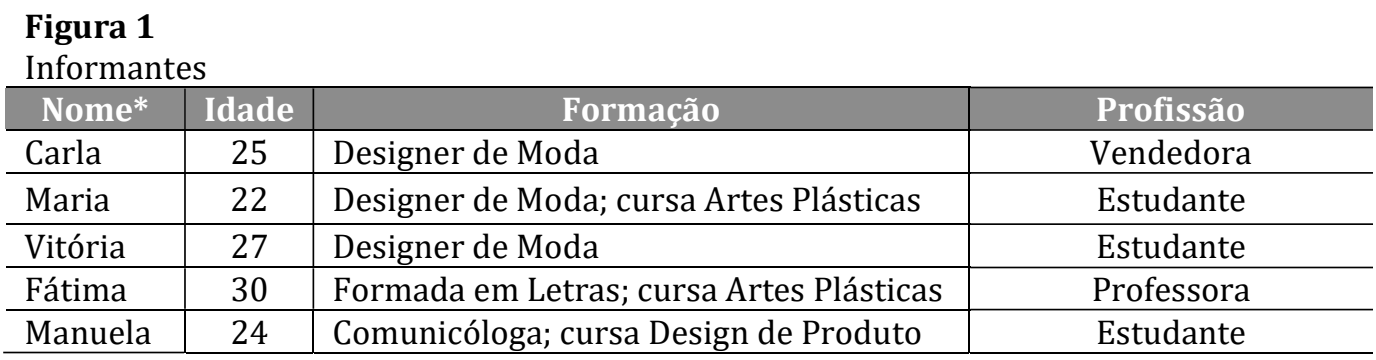




\begin{tabular}{l|c|l|c}
\hline Tereza & 22 & Cursa Direito & Estudante \\
\hline Márcia & 36 & Cursa Direito & Revisora de Textos \\
\hline Viviane & 26 & Cursa Arquitetura & Estudante \\
\hline Joana & 39 & -- & Funcionária Pública \\
\hline Laura & 31 & Doutoranda em História & Estudante \\
\hline Luiza & 33 & Cursa Arquitetura & Proprietária de brechó \\
\hline Paula & 44 & Formada em Moda & Proprietária de brechó \\
\hline Valentina & 35 & -- & Proprietária de brechó \\
\hline
\end{tabular}

Fonte: Elaborado pelos autores. Nota. * Nome fictício dado às entrevistadas com o objetivo de proteger a identidade.

As entrevistas em profundidade foram realizadas como uma conversa especial, envolvendo um interesse no que a outra pessoa tem a dizer e um fluxo coerente de tópicos, possibilitando descrições profundas do fenômeno estudados (Belk, Fischer, \& Kozinets, 2013). As entrevistas possibilitaram uma compreensão ampla do problema de pesquisa, sendo um instrumento significativo para acessar as crenças, valores e práticas de consumo dos informantes (Fischer, Castilhos, \& Fonseca, 2014). As entrevistas exploraram tópicos emergentes de interesse e relevância para a pesquisa (Belk, Fischer, \& Kozinets, 2013).

Os dados coletados durante a pesquisa foram analisados pelos dois autores seguindo a abordagem hermenêutica (Belk, Fischer, \& Kozinets, 2013; Thompson, 1997), no qual os significados são constituídos e transmitidos por meio das narrativas. A hermenêutica tem como um dos princípios fundamentais a compreensão de que o entendimento é baseado na linguagem, sendo que o mundo cultural no qual vivemos molda nossos conhecimentos (Belk, Fischer, \& Kozinets, 2013). Esse mundo cultural implica no acúmulo de crenças, teorias, códigos, metáforas, práticas, ideologias, instituições e mitos, que influenciam na forma pela qual iremos interpretar os dados coletados em um estudo (Belk, Fischer, \& Kozinets, 2013). Tipicamente, as contribuições teóricas dessa tradição de pesquisa envolvem análises de elementos culturais importantes na formação do pensamento e do comportamento (Belk, Fischer, \& Kozinets, 2013).

0 processo de análise dos dados começou com a netnografia, onde foi possível iniciar uma apreciação sobre a forma como os consumidores expressavam a sua relação com o contexto e com outros consumidores. Na fase das entrevistas, à medida que o trabalho se desenvolveu, foi possível focar os esforços para compreensão dos temas êmicos (Thompson, 1997) presentes nas narrativas das informantes. $\mathrm{O}$ avanço do estudo proporcionou uma perspectiva de temas éticos, no qual buscamos contextualizar as narrativas dos participantes em um contexto sociocultural mais amplo (Thompson, 1997).

\section{SINGULARIZAÇÃO DOS OBJETOS DE SEGUNDA MÃO}

A análise dos dados coletados propiciou a descrição do movimento dos objetos no mercado de segunda mão. Este mercado é circular. As peças entram no brechó para serem vendidas e são compradas por outras consumidoras formando um círculo contínuo de consumo. No entanto, diante do objetivo da pesquisa, nosso trabalho focou no momento que a peça mercantilizada é vendida no brechó de luxo e retoma o seu status de singularizada. Muitos dos objetos vendidos no brechó de luxo são singularizados novamente pelas consumidoras e adquirem status de objetos únicos, singulares e muito valorizados.

0 processo de nova singularização de um objeto usado é especialmente significativo, uma vez que a consumidora o retira do seu status de mercadoria no brechó e enaltece as características específicas da peça que são especiais. A partir disso, o objeto mercantilizado se movimenta e começa a fazer parte novamente de uma rede de objetos singularizados pelas consumidoras. Nesse contexto, duas estratégias são utilizadas pelas lojas de brechó e pelas consumidoras na tentativa de singularizar novamente os objetos de segunda mão, são elas: (1) resgate da biografia e (2) potencial de diferenciação. Estes aspectos serão explicitados nos tópicos a seguir. 


\section{Resgate da Biografia do Objeto}

Os informantes buscam roupas de segunda mão com alguma história por ser um símbolo de um estilo, de uma época, ou cultura específica. As roupas de segunda mão permitem que algumas consumidoras perpetuem a memória do objeto e mantenham alguma continuidade (Roux, 2006). A história de vida do objeto é materializada nos seus contornos, traços, tipos de cortes e panos revelando seu tempo e época. No fragmento abaixo a consumidora Laura relata que não vê problema em comprar uma peça que já esteja com algum sinal de uso, já que "faz parte da história da peça", segundo ela.

Eu compro muitas vezes peças que estão bem 'baleadas', dependendo do estrago eu compro mesmo assim, às vezes customizo, dá um jeito (...) muito difícil você achar uma peça mais antiga intacta, sem um rasgadinho, uma manchinha e eu acho que muitas vezes a mancha faz parte da história da peça, eu não ligo muito não pra mancha assim sabe, faz parte, é a história, essa peça passou por algo que a levou a ter aquela marca, então...eu lembro que eu tenho uma camisa que ela tem um furinho de cigarro assim, a pessoa às vezes encostou ne... às vezes alguém me pergunta 'você fuma?' 'não', a pessoa que usou que furou ne...mas assim geralmente é difícil você achar peças muito antigas que estejam em perfeito estado. (Laura).

Na biografia de um objeto, diversos acontecimentos transmitem significados à coisa. De acordo com Kopytoff (2008) questões devem ser colocadas ao fazer a biografia de um objeto, similarmente como se faz com a biografia de pessoas. Por exemplo: De onde vem a coisa e quem fabricou? Qual foi a sua carreira até aqui e qual é a carreira que as pessoas consideram ideal para esse tipo de coisa? Quais são as "idades" ou as "fases da vida" reconhecidas de uma coisa e quais são os mercados culturais para elas? Como mudam os usos da coisa conforme ela fica mais velha, e o que lhe acontece quando sua utilidade chega ao fim? A biografia do objeto é construída historicamente de forma oral e materializada na própria peça. A fala da informante Joana ressalta a importância da história da roupa, ou biografia do objeto.

Eu acho legal esse movimento do desapego e de ao mesmo tempo renovar as coisas sabe...porque se perde muita coisa que o mercado vai te trazendo assim, a coisa do novo, do novinho, da etiqueta...de não poder ter um rasgado, um fio puxado e você vê que a roupa não é isso só, eu acho que a roupa é muito mais. E, pra mim, a roupa antiga...roupa tem que contar uma história, eu tenho que contar uma história através da minha roupa ne, que é quando eu visto, de me fantasiar mesmo. (Joana)

A biografia das coisas pode ter várias perspectivas como física, econômica, técnica, social, inclusive cultural. A biografia culturalmente informada e construída é dotada de significados específicos e classificada em categorias culturalmente constituídas (Kopytoff, 2008). Por isso, se faz necessário que se conheça todas as fases de vida da biografia de um objeto e não somente a sua origem, produção, os momentos de troca ou o seu descarte final, sendo importante o regaste da história do objeto em todas as fases de sua vida.

O brechó de luxo é o local no qual as consumidoras encontram as peças de segunda mão que são imbuídas de significados e história. Os comerciantes se envolvem nesse processo e conferem significados à esses bens. A proprietária de um dos brechós visitados, Paula, relata sobre a história de uma peça específica, enaltecendo suas características e a forma como a peça foi feita, indicando que é uma peça especial e exclusiva, como pode ser visto abaixo: 
A modelagem me chama mais atenção nas peças vintage, a modelagem antiga é mais...alta costura assim...o tecido também, a textura (...) esse casaquinho aqui mesmo, você vê que nem tem etiqueta, foi feito por costureira mesmo...a lã é bem grossa e você bate o olho e vê que não é uma coisa atual. E o que te transfere esse sentimento? É a modelagem...se fosse uma releitura exatamente com a mesma modelagem, o tecido já não seria o mesmo, você vê que a lã tem uma textura diferente (...) é diferenciado mesmo, a costura feita à mão, a modelagem...a peça era feita com mais cuidado assim (...) não é que as modelagens hoje não sejam boas não, mas como eram feitas pouquíssimas peças de cada, é especial, você sente um cuidado na peça, você sabe que foi feita aquela sozinha (...) quando você chega num brechó, você consegue reconhecer essa qualidade das coisas muito antigas. Sem contar a história, 'olha só que legal, minha mãe usava e eu quero usar hoje', volta às raízes assim. (Paula)

No relato da informante e comerciante Luiza fica claro que o brechó é o local onde as peças usadas são dotadas de um novo significado.

Então tem uma história social além de estética de vc usar uma roupa que não foi produzida agora, né? Não que isso não acontecesse antes, mas assim se ela já está sendo revendida, ela já passou por um processo assim de desvalorização, ela está sendo revalorizada e ressignificada. (Luiza)

O brechó é o lugar onde o objeto usado é mercantilizado, isto é, ele volta para o mercado, mas são revestidos de significado por meio da reconstrução da sua biografia de vida realizada pelos comerciantes do brechó. Dessa forma, as peças usadas podem ser singularizadas novamente pelas consumidoras, que enaltecem os aspectos específicos da peça como as características físicas, peculiaridade e distinção.

\section{Potencial de Diferenciação do Objeto}

0 contexto cultural do objeto, o valor estético, científico, as características autênticas, ou ainda, o valor sentimental pessoal atribuem aos objetos a sua singularização. No entanto, isso é possível a partir do conhecimento do indivíduo que está tornando aquele objeto singularizado. Este aspecto é evidenciado na fala da entrevistada abaixo, a consumidora Viviane retrata seu conhecimento quando citam o acabamento das roupas, a questão estética, o caimento e os tecidos:

São principalmente vintage. Eu gosto muito das estampas sabe, camisas com estampas diferentes, geométricas ou coloridas. Às vezes o padrão do tecido que vem com umas tachinhas diferentes, que não são comuns...às vezes roupas de estilos de décadas passadas.... que é divertido tentar fazer delas uma coisa usável atualmente...e é isso. Eu acho que o que mais me atrai na questão estética dos brechós são as estampas. (Viviane)

A blogueira Carol, no trecho abaixo, fala para suas leitoras como descobrir o "potencial fashion" de cada peça encontrada em brechós. E mostra ainda possíveis combinações com a peça comprada no brechó. Por meio dessa postagem ela busca evidenciar seu conhecimento em moda, utilizando o contexto do valor estético da peça. 
0 que faz a diferença entre achar ou não roupas legais é a nossa capacidade de perceber o "potencial fashion" que aquela roupa pode ter. Eu não tenho memória para nada, mas para o que eu tenho no meu armário...minha mente decora muito bem! hahaha Então quando vejo uma peça, já consigo montar diversos looks possíveis para ela. Se eu não conseguir encontrar "mentalmente" esses looks, eu não compro por que sei que vai ser dinheiro jogado fora. (...) algumas roupas que super funcionam e combinam com muita coisa que tem no meu armário. Para mostrar melhor esse "potencial fashion" montei umas sugestões de looks pra vocês verem! (Carol, trecho retirado do blog Carol Burgo, 2013)

A blogueira Jojo relata detalhes de duas peças que ela adquiriu em um brechó e ressalta ainda a década em que cada peça foi fabricada. Isto demonstra que ela possui conhecimento sobre moda e suas leitoras também.

Acho que o melhor jeito de introduzir esse look é mesmo com uma pergunta: Como não amar? Sério. É um macacão. Rosa. Estampado. Dos anos 80. Precisa dizer mais alguma coisa? Acho que posso falar também sobre como encontrei essa pérola. É o seguinte. Toda vez que eu entro num brechó, especialmente um que seja muito abarrotado e um tantinho desorganizado, eu foco em cores e estampas. (Jojo, trecho retirado do blog UASZ, 2017)

Consumidores que desejam se diferenciar, demonstrar sua individualidade e que possuem uma forte necessidade de singularidade são mais propensos a fazer escolhas não tradicionais, isto é, optam por comprar em canais secundários, por exemplo, em brechós ou bazares que ofertam objetos de segunda mão (Xu, Yizhuo, Ritika, \& Hongshan, 2014). A raridade de encontrar um item exclusivo e extraordinário agrada esses consumidores que desejam ser únicos (Brace-Govan \& Binay, 2010).

A possibilidade de se distinguir por meio da das roupas de segunda mão são características atraentes para os consumidores de brechós de luxo (Ferraro, Sands, \& Brace-Govan, 2016). Maior quantidade de capital cultural facilitam a rejeição de significados impostos pela cultura dominante, de modo que as escolhas de consumo e as preferências de gosto se tornem mais genuínas (Arsel \& Thompson, 2011; Mcquarrie, Miller, \& Phillips, 2013).

A roupa de segunda mão ressoa esses valores de exclusividade para os consumidores, transformando o significado e apoiando a formação de identidade desses indivíduos (Brace-Govan \& Binay, 2010). No caso da moda de segunda mão, a singularidade está ligada à importância da roupa ser "única", já que há uma chance muito pequena de que qualquer outra pessoa tenha exatamente a mesma peça (Brace-Govan \& Binay, 2010). A consumidora e proprietária de um brechó Luiza comprova isso em sua fala abaixo:

Olha eu só compro roupa de brechó (risos) primeiro porque como eu tenho essa paixão mesmo pelas roupas, são peças únicas ne... muito difícil você achar uma roupa de brechó que vai ter outra igual, porque mesmo se forem roupas industrializadas as pessoas que se desapegam não moram nos mesmos lugares, acho praticamente impossível achar roupas iguais no brechó (...) e o brechó é o mundo do singular, o que você encontra no brechó você não vai encontrar em outro lugar. (Luiza)

A necessidade do consumidor de expressar sua originalidade em um ambiente social se relacionada com o grau de auto percepção de singularidade em relação aos outros indivíduos ou grupos, nesse sentido, a busca por singularidade reflete na aquisição, utilização e disposição dos bens de consumo com o objetivo de desenvolver e/ou melhorar a própria imagem social. Os consumidores 
se envolvem em atividades de consumo, como roupas de moda, em busca de melhorar sua percepção de singularidade e distinção.

\section{CONSIDERAÇÕES FINAIS}

Nossa pesquisa aprofunda a discussão sobre cultura de consumo no Brasil (Suares \& Casoti \& Suarez, 2016; Valentim, Falcão, \& Campos, 2017) avançando sobre a explicação em relação ao movimento dos objetos: como escolhemos, revestimos de significados pessoais e, assim, os retiramos do status de mercadoria (Belk, Wallendorf, \& Sherry, 1989; Kopytoff, 2008; Miller, 2007). Há também pesquisas que investigam sobre como acontece o movimento dos objetos quando retornam à esfera mercantil, sendo mercantilizados novamente ou descartados (Epp \& Price, 2010; Herrmann, 1997; Lastovicka \& Fernandez, 2005).

Nosso trabalho explica as estratégias utilizadas pelas lojas de brechó e consumidoras para que objetos de segunda mão retomem seu status singularizado, examinando como estes objetos transitam entre o estado de mercadoria e de produto singularizado durante sua trajetória de vida. A biografia do objeto de segunda mão é evidenciada nos brechós, onde os comerciantes imbuem as peças de significados e história com o objetivo de adicionar valor de mercado ao objeto de segunda mão. Por outro lado, as consumidoras buscam potenciais de diferenciação nas peças vendidas nos brechós de luxo. Os atributos específicos das peças de segunda mão tais como tecido único, estampa diferenciada, alta qualidade e determinado estilo interessam às consumidoras, tendo a oportunidade, dessa forma, de expressar seus conhecimentos de moda.

Os resultados aqui apresentados são úteis, não somente para o mercado de roupas e acessórios de segunda mão, mas também para o mercado de objetos usados de forma geral. Este fenômeno de consumo se manifesta em diversos países por meio das vendas de garagens, lojas de segunda mão, cadeias de varejo especializadas e os sites na Internet (Guiot \& Roux, 2010).

Para pesquisas posteriores, propõe-se a utilização dos conceitos aqui empregados em uma investigação em brechós e mercados de roupas e acessórios de segunda mão online, com o intuito de se compreender o comportamento do consumidor em outros canais de venda. Ademais, seria interessante analisar o movimento dos objetos usados em outros mercados, verificar se as estratégias de singularização são as mesmas e de que forma os objetos transitam em outros contextos.

\section{Referências}

Appadurai, A. (2008). A vida social das coisas: as mercadorias sob uma perspectiva cultural. Niterói: Editora da Universidade Federal Fluminense.

Arsel, Z. \& Thompson, C. J. (2011). Demythologizing consumption practices: How consumers protect their field-dependent identity investments from devaluing marketplace myths. Journal of Consumer Research, 37(5), 791-806.

Batinga, G. L., Pinto, M. De R., \& Guimarães, L. De V. M. (2019). Por uma compreensão do mundo material: uma biografia da marca Apple. Cadernos EBAPE, 17(2), 263-276.

Belk, R. W. (1988). Possessions and the extended self. Journal of Consumer Research, 15(2), 139-168.

Belk, R., Wallendorf, M., \& Sherry Jr, J. (1989). The sacred and the profane in consumer behavior: Theodicy on the odyssey. Journal of Consumer Research, 16(1), 1-38.

Belk, R., Fischer, E., \& Kozinets, R. V. (2013). Qualitative consumer and marketing research. London, UK: Sage Publications.

Borgerson, J. (2005). Materiality, agency, and the constitution of consuming subjects: insights for consumer Research. Advances in Consumer Research, 32, 439-443.

Bourdieu, P. A. (2015). Distinção: crítica social do julgamento. Porto Alegre: Editora Zouk.

Brace-Govan, J., \& Binay, I. (2010). Consumption of disposed goods for moral identities: a nexus of organization, place, things and consumers. Journal of Consumer Behaviour, 9(1), 69-82.

Casotti, L. M. \& Suarez, M. C. (2016). Dez anos de consumer Culture Theory: Delimitações e aberturas. Revista de Administração de Empresas, 56(3), 353-359. 
Curasi, C. F., Price, L. L., \& Arnould, E. J. (2004). How individuals' cherished possessions become families' inalienable wealth. Journal of Consumer Research, 31(3), 609-622.

Epp, A. M., \& Price, L. (2010). The storied life of singularized objects: Forces of agency and network transformation. Journal of Consumer Research, 36(5), 820-837.

Fernandez, K. V., \& Lastovicka, J. L. (2011). Making magic: Fetishes in contemporary consumption. Journal of Consumer Research, 38(2), 278-299.

Ferraro, C., Sands, S., \& Brace-Govan, J. (2016). The role of fashionability in second-hand shopping motivations. Journal of Retailing and Consumer Services, 32, 262-268.

Guiot, D. \& Roux, D. A. (2010). Second-hand shoppers' motivation scale: Antecedents, consequences, and implications for retailers. Journal of Retailing, 86(4), 355-371.

Herrmann, G. M. (1997). Gift or commodity: What changes hands in the US garage sale? American Ethnologist, 24(4), 910-930.

Kopytoff, I. (2008). A biografia cultural das coisas: a mercantilização como processo. In: Appadurai, A, A vida social das coisas. Niterói: Editora da Universidade Federal Fluminense.

Kozinets, R. V. (2014). Netnografia: realizando pesquisa etnográfica online. Porto Alegre: Penso Editora.

Lastovicka, J. L. \& Fernandez, K. V. (2005). Three paths to disposition: The movement of meaningful possessions to strangers. Journal of Consumer Research, 31(4), 813-823.

Mcquarrie, E. F., Miller, J., \& Phillips, B. J. (2013). The megaphone effect: Taste and audience in fashion blogging. Journal of Consumer Research, 40(1), 136-158.

Miller, D. (2007). Consumo como cultura material. Horizontes antropológicos, 13(28), 33-63.

Roux, D. \& Guiot, D. (2008). Measuring second-hand shopping motives, antecedents and consequences. Recherche et Applications en Marketing (English Edition), 23(4), 63-91.

Roux, D. (2006). Am I what I wear? An exploratory study of symbolic meanings associated with secondhand clothing. Advances in Consumer Research, 33, 29-35.

Sherry Jr, J. F. (1990). A sociocultural analysis of a Midwestern American flea market. Journal of Consumer Research, 17(1), 13-30.

Thompson, C. J. (1997). Interpreting consumers: a hermeneutical framework for deriving marketing insights from the texts of consumers' consumption stories. Journal of Marketing Research, 34(4), 438-455.

Turunen, L. L. M., \& Leipämaa-Leskinen, H. (2015). Pre-loved luxury: identifying the meanings of second-hand luxury possessions. Journal of Product \& Brand Management, 24(1), 57-65.

Valentim, P. P., Facão, R. P. De Q., \& Campos, D. R. (2017). 0 corpo nos estudos de consumo: Uma revisão bibliográfica sobre o tema. Consumer Behavior Review, 1(Special Edition), 32-48.

Williams, C. C., \& Paddock, C. (2003). The meanings of informal and second-hand retail channels: some evidence from Leicester. The International Review of Retail, Distribution and Consumer Research, 13(3), 317-336.

Xu, Y., Yizhuo, C., Ritika, B., \& Hongshan, Z. (2014). Second-hand clothing consumption: a cross-cultural comparison between American and Chinese young consumers. International Journal of Consumer Studies, 38(6), 670-677. 